\title{
Success of uterine artery embolization in the management of postabortal arteriovenous malformations
}

\author{
Sunil Kumar Juneja, Pooja Tandon*, Gagandeep Kaur
}

Department of Obstetrics and Gynecology, Dayanand Medical College and Hospital, Ludhiana, Punjab, India

Received: 17 December 2019

Revised: 16 January 2020

Accepted: 24 January 2020

\author{
*Correspondence: \\ Dr. Pooja Tandon, \\ E-mail: drpoojatandon77@gmail.com
}

Copyright: () the author(s), publisher and licensee Medip Academy. This is an open-access article distributed under the terms of the Creative Commons Attribution Non-Commercial License, which permits unrestricted non-commercial use, distribution, and reproduction in any medium, provided the original work is properly cited.

\begin{abstract}
Background: Uterine artery arteriovenous malformations are an abnormal and non-functional connection between the uterine arteries and veins. It may be congenital or acquired. AVM can cause heavy menstrual bleeding and may have an impact on infertility. Uterine artery embolization is an alternate method to hysterectomy preserving the menstrual and reproductive function. Objectives of this study was to diagnose Arterio-venous malformations after abortions in patients with heavy menstrual bleeding and treating these patients with UAE.

Methods: The retrospective study of patients with postabortal arteriovenous malformations managed at Dayanand Medical College and Hospital, during January 2012 to December 2018 was done. Inclusion criteria for this study post abortal heavy menstrual bleeding patients in reproductive age group diagnosed to be having AV malformations on CT angiography. Exclusion criteria for this study were H/O AUB prior to abortion, patients with fibroids, PID, endometriosis, adenomyosis, genital tract malignancies. Patients who do not have AV malformations on CT angiography.

Results: This is a retrospective seven years study between January 2012 to December 2018 during which we received 23 patients who developed arterio-venous fistula following an abortion. The patients had heavy menstrual bleeding. All the patients had taken some hormonal treatment before reporting to us. All these patients underwent CT angiography. After that they all were subjected to UAE. All these patients were followed up to 6 months where they showed improvement in the symptoms.

Conclusions: Acquired AVM is rare disorder following an abortion or a caesarean section. Heavy menstrual bleeding is a common symptom often requiring hysterectomy but with the advent of uterine artery embolization by blocking the uterine artery we can conserve the uterus where a lady can have normal menstrual and reproductive functions.
\end{abstract}

Keywords: Arteriovenous, CT angiography, Heavy menstrual bleeding, Malformation, Postabortal, Uterine artery embolization

\section{INTRODUCTION}

Uterine arteriovenous malformations are an abnormal and non-functional connection between the uterine arteries and veins. It may be congenital or acquired. True incidence of AVM is not known but the incidence is definitely rising following abortion, caesarean section, myomectomy and curettage. ${ }^{1}$ AVM can be found anywhere in the vascular system, including the uterus. AVM can cause heavy menstrual bleeding and metrorrhagia and sometimes life threatening bleeding and may have an impact on infertility as well. ${ }^{2}$ The treatment of choice depends on the symptoms, age, desire for future fertility, and localization and size of the lesion; however, 
embolization of the uterine artery is the first choice in symptomatic AVM patients in reproductive age with expectations of future fertility. ${ }^{3,4}$ Hysterectomy used to be the definite treatment earlier prior to the advent of uterine artery embolization. Uterine artery embolization is an alternate method to hysterectomy preserving the menstrual and reproductive function. UAE was first reported in 1995.5 Uterine arteries are cannulated in a retrograde approach through femoral arteries under fluoroscopy guidance and are embolised either with gel form, polyvinyl particles or coils. ${ }^{6}$

Objective of this study was to diagnose Arterio-venous malformations after abortions in patients with heavy menstrual bleeding and treating these patients with UAE.

\section{METHODS}

This is a retrospective study conducted on patients presenting with heavy menstrual bleeding following a surgical abortion, between January 2012 to December 2018. During this period, we diagnosed twenty-three patients as having arterio-venous fistula developed following an abortion. The patients who presented with heavy menstrual bleeding following abortion had taken some hormonal treatment before reporting to us. All these patients had been advised hysterectomy outside. We subjected all these patients to USG with Doppler flowmetery and CT angiography. The USG could not pick all AVMs hence the patients were subjected to CT angiography. All the patients with AVM underwent UAE as minimal invasive treatment.

\section{Inclusion criteria}

- Post abortal heavy menstrual bleeding patients in reproductive age group diagnosed to be having AV malformations on CT angiography.

\section{Exclusion criteria}

- H/O AUB prior to abortion, patients with fibroids, PID, endometriosis, adenomyosis, genital tract malignancies

- Patients who do not have AV malformations on CT angiography.

\section{Statistical analysis}

Data were described in terms of range; frequencies (number of cases) and relative frequencies (percentages) as appropriate. All statistical calculations were done using SPSS (statistical package for the social science) SPSS 17 version statistical program for Microsoft Windows.

\section{RESULTS}

The retrospective study of patients presenting with heavy menstrual bleeding following abortion diagnosed as arteriovenous malformations on CT angiography managed at Dayanand Medical College and Hospital during January 2012 to December 2018 was done. All the patients with AVM underwent UAE as minimal invasive treatment.

Table 1: Distribution of patients according to age.

\begin{tabular}{|ll|}
\hline Age-group & Number of patients \\
\hline $23-26$ years & 14 \\
\hline $27-29$ years & 7 \\
\hline $30-33$ years & 1 \\
\hline $34-37$ years & 1 \\
\hline Total & 23 \\
\hline
\end{tabular}

All these patients were followed up for 6 months during which they showed significant improvement in their symptoms. During the study 14 patients were between the age group of 23-26 year, seven patients were between 2629 years, whereas one patient each was there in age group between 30-33 years and 34-37 years (Table 1).

Table 2: Distribution of patients according to femoral access for UAE.

\begin{tabular}{|ll|}
\hline & Number of patients $(\mathbf{N}=\mathbf{2 3})$ \\
\hline Unilateral UAE & 18 \\
\hline Bilateral UAE & 5 \\
\hline
\end{tabular}

Out of 23 patients 18 patients underwent unilateral UAE where as five patients underwent bilateral UAE (Table 2).

Table 3: Distribution of patients according to the embolic material used in UAE.

\begin{tabular}{|ll|}
\hline Embolic material used & $\begin{array}{l}\text { Number of patients } \\
(\mathbf{N}=\mathbf{2 3})\end{array}$ \\
\hline Polyvinyl alcohol particles & 19 \\
\hline Metallic coils & 4 \\
\hline
\end{tabular}

During UAE, in 19 patients out of 23, polyvinyl particles were used for embolization whereas four patients needed metallic coils (Table 3 ).

Table 4: Distribution of patients according to obstetrical history.

\begin{tabular}{|ll|}
\hline & Number of patients $(\mathrm{N}=\mathbf{2 3})$ \\
\hline $\mathrm{P}_{1} \mathrm{~A}_{1}$ & 14 \\
\hline $\mathrm{P}_{2} \mathrm{~A}_{1}$ & 7 \\
\hline $\mathrm{P}_{3} \mathrm{~A}_{2}$ & 2 \\
\hline
\end{tabular}

Out of 23 patients, 14 patients were P1A1; seven were P2A1 and two patients P3A2 (Table 4).

All the patients were followed up till six months and there was no recurrence of symptoms in any of the patients. 


\section{DISCUSSION}

Arteriovenous malformation (AVM) of the uterus is a rare cause of heavy menstrual bleeding. It may at times lead to life-threatening bleeding. The clinical findings may not always be reliable in the diagnosis of uterine AVM, and a high index of suspicion is important because, unlike many other causes of menorrhagia, curettage may paradoxically aggravate the bleeding. ${ }^{4}$

Uterine AVMs can be congenital or acquired. There are many causes associated with acquired uterine AVMs which include previous cesarean surgery, dilatation and curettage, pelvic trauma, malignancy. It may be associated with infection or inflammation. ${ }^{7}$

The majority of reported cases are acquired secondary to dilation and curettage. ${ }^{2}$ Pathophysiological differences do exist between congenital and acquired varieties. Congenital uterine AVMs are characterized by multiple feeding arteries, a central nidus consisting of vessels with characteristics of both arteries and veins, and multiple large draining veins. In contrast, acquired uterine AVMs consist of one or more arteriovenous fistulas between intramural arterial branches and the myometrial venous plexus. $^{8}$

Pelvic angiography remains the gold standard for diagnosis of a uterine AVM. ${ }^{7}$ Other imaging modalities of importance include pelvic magnetic resonance imaging and computed tomography angiography. ${ }^{9}$

Management of uterine AVMs depends on factors like patient's hemodynamic status, age, and desire for conserving the uterus. Different embolic materials have been used in successfully preserving the uterus. ${ }^{7}$ Hysterectomy used to be the choice before the advent of uterine artey embolization. ${ }^{10}$

\section{CONCLUSION}

Acquired AVM is rare disorder following an abortion. Heavy menstrual bleeding is a common symptom often requiring hysterectomy in the past but with the advent of uterine artery embolization by blocking the uterine artery we can conserve the uterus where a woman can have normal menstrual and reproductive functions.

If a patient comes with heavy menstrual bleeding or irregular continuous bleeding after an abortion and does not respond to medical treatment must get CT angiography done to rule out an AVM which may be missed on ultrasound with Doppler.
Funding: No funding sources

Conflict of interest: None declared

Ethical approval: The study was approved by the Institutional Ethics Committee

\section{REFERENCES}

1. Vilos AG, Vilos GA, Hollett-Caines J, Rajakumar C, Garvin G, Kozak R. Uterine artery embolization for uterine arteriovenous malformation in five women desiring fertility: pregnancy outcomes; Human Reprod. 2015;30(7):1599-605.

2. Evans A, Gazaille RE, McKenzie R, Musser M, Lemming R, Curry $\mathrm{J}$, et al. Acquired uterine arteriovenous fistula following dilatation and curettage: an uncommon cause of vaginal bleeding; Radiol Case Reports. 2017;12(2):287-91.

3. Karadag B, Erol O, Ozdemir O, Uysal A, Alparslan AS, Gurses C, et al. Successful treatment of uterine arteriovenous malformation due to uterine trauma. Case Reports Obstet Gynecol. 2016:Article ID 1890650.

4. Molvi SN, Dash K, Rastogi H, Khanna SB. Transcatheter embolization of uterine arteriovenous malformation: report of 2 cases and review of literature. J Minim Invasive Gynecol. 2011;18(6):812-9.

5. Kohi MP, Spies JB. Update on uterine artery embolization. Semin Intervent Radiol. 2018;35(1):48-55.

6. Annam A. Female pelvic vascular malformations. Semin Intervent Radio. 2018;35(1):62.

7. Fleming $H$, Ostor AG, Picket $H$, Fortune AG. Arteriovenous malformations of the uterus. Obstet Gynecol. 1989;73-209-14.

8. Cura M, Martinez N, Cura A, Dalsaso TJ, Elmerhi F. Arteriovenous malformations of the uterus. Acta Radiol. 2009;50(7);823-9.

9. Grivell RM, Reid KM, Mellor A. Uterine arteriovenous malformations; a review of the current literature. Obstet Gynaecol Surv. 2005;60(11);61-7.

10. Bonduki CE, Feldner PC, Silva JD, Castro RA, Sartori MG, Girao MJ. Pregnancy after uterine artery embolization. Clinics (Sao Paulo). 2011;66(5):80710 .

Cite this article as: Juneja SK, Tandon P, Kaur G. Success of uterine artery embolization in the management of postabortal arteriovenous malformations. Int J Reprod Contracept Obstet Gynecol 2020;9:981-3. 